\title{
Evaluation on ESQ 165 Training as Spiritual-Engineering-Based Motivation Training in an Attempt to Build the Character of the Members of the Subregional Police of Ciamis
}

\author{
Irawati, Ira ${ }^{a}$ and Runiawati, Nunung ${ }^{a}$
}

${ }^{\mathrm{a}}$ Public Administration Department, Padjadjaran University, Indonesia.

\begin{abstract}
The reform of the Indonesian National Police (Polri) requires the change in the behaviour of its members to be more professional in their service to the public. ESQ 165 Training is chosen as one of the programs in an attempt of character building of the members of the Subregional Police (Polres) of Ciamis. ESQ 165 Training is character-building training categorized as a type of motivation training which uses comprehensive and sustainable spiritual engineering. This research aims to evaluate ESQ 165 Training in an attempt to build the character of the members of the Subregional Police of Ciamis. The theory utilized in this research is Kirkpatrick's Framework which consists of four studied levels, namely reaction level, learning level, behavioural level, and result level. This research uses a quantitative descriptive research method. Data-gathering technique uses questionnaires distributed among 223 members of the Subregional Police of Ciamis who have participated in ESQ 165 Training, observation and interviews. The result of the research shows that $88 \%$ of respondents likes the training (reaction level), 93\% of respondents understand the material of training (learning level), respondents shows changes in motivation, attitude and behaviour (behaviour level), and the public appreciate the performance of the Subregional Police of Ciamis which has undergone significant changes (result level). Therefore, ESQ 165 Training can be recommended as one of training methods utilized in character building.
\end{abstract}

Keywords: Training, ESQ 165, Motivation, Spiritual Engineering, Character Building, the Subregional Police of Ciamis. 


\section{Introduction}

The reform of the Indonesian National Police (Polri) has been conducted since 2000, marked by the separation of the police organization from the military circle to become democratic civil police. The greatest challenge faced by the Indonesian National Police after the reform is the alteration of culture from a military-based institution to a civil one which respects the norms of democracy, such as equality, justice, independency and transparency.

Some efforts have been conducted by the Indonesian National Police to improve its performance, among other things, by creating grand design of 2005-2025. The grand design is divided into three strategic stages. Stage I (2005-2009) has the goal of trust building; stage II (2010-2014) has the goal of partnership building and; stage III (2015-2025) is aimed to strive for excellence (Note of Public Relation Division of Headquarters of the Indonesian National Police, 2011). In order to realize the grand design, the alteration of culture is required. The alteration of culture is required in view of the image that will be built, namely the police which is close to the public, in which the public are considered as the partner so that the police must be proactive and not repressive in involving the public. The character of arrogance, namely the authoritarian approach used to be utilized by the police, is returned to the initial track as the protector, guardian and servant of the public.

The change of culture is not only about the knowledge, but it also needs to be touched at the heart and spirituality. Spiritual dimension also becomes one of the basic principles of life as a nation and as a state as stated in the first principle of Pancasila (the national principle), namely belief in the one and only God. Therefore, since 2011 the Indonesian National Police has signed a memorandum of understanding (MoU) with ESQ Leadership Center. ESQ Leadership Centre (ESQ LC) is a training institution of human resources which has been established since 2000 with the total number of alumni of 1.4 million of all over the world. ESQ Leadership Training creates training known as ESQ 165 Training. ESQ 165 Training is considered relevant to the need of the Indonesian National Police because it uses the method of spiritual engineering which is comprehensive and sustainable in character building.

Locus of this research is the Subregional Police of Ciamis (Polres Ciamis), which is a command structure the Indonesian National Police in the Regency of Ciamis, West Java Province, Indonesia. Since 2015 Chief of the Subregional Police of Ciamis has had a policy to make more than $62 \%$ of its members to participate in ESQ 165 Training. This research is aimed to evaluate ESQ 165 training in an attempt to build the character of the members of the Subregional Police of Ciamis.

The type of ESQ 165 Training given to the members of the Subregional Police of Ciamis is ESQ 165 Training of character building 1 (personal transformation), which is the ESQ basic training among the four types of training conducted by ESQ LC. This training can be categorized as a type of motivation training that uses comprehensive and sustainable spiritual engineering. This training is aimed to build the character by combining 3 potentials of human beings, namely intellectual, emotional and spiritual quotients. Combination of the three characters answers the current basic problem in the government, especially ethics and morality. 
ESQ basic training will transform the participant's paradigm on the meaning of happiness and work. If thus far, the meaning of happiness is just a material and emotional thing, then through this training the participants will be invited to find another kind of happiness, which is called spiritual happiness, so that their life will be more meaningful and more precious. Each training has a unique character, in which the alumni are allowed to participate again in the same type of training for free. It is the after sales service provided by ESQ LC to its alumni considering the success of character building cannot be instantly determined because it is a continuous, multistage and multiphase process.

The two days training is attractively presented by using sophisticated multimedia. Meanwhile, the goal of the day one is zero mind process, that is, to erase pride and egoism to be able to return to pure mind (God Spot) which is the base of emotional and spiritual quotients. The training material of the day two is focused on the character building through the 7 main virtues, i.e., honest, responsible, visionary, discipline, cooperative, righteous and caring.

\section{Literature Review}

Several studies on human resource development (HRD) program have been developed with the purpose to intervene the employee behaviour according to the expectation of the organization because "HRD has an important rolein generating improved organizational performance and individual growth"(Stone 2005). Therefore, HRD professionals must be able to determine the most suitable program in order to improve the performance of the organization and the employees' capacity.

Basic information that must be known by the HRD professionals before determining the most suitable program is the factors that can affect the employee behaviour. DeSimone and Werner stated that "there are two key factors affecting employee behaviour, (1) external forces-that is, those found in the external environment and work environment and (2) internal forces-that is two within the employee, including motivation, attitudes, and KSAs (knowledge, skills, and abilities)"(2012). Motivation and attitudes are the aspects that cannot be changed easily, while KSAs are the factors that can be changed easily, one of them through education and training. In the context of this research, the training is focused on the internal forces, particularly on the aspect of motivation as one of the most basic element of human behaviour (DeSimone and Werner, 2012).

Evaluation on ESQ training in the Subregional Police of Ciamis uses Kirkpatrick's Framework. Kirkpatrick states that there are 4 levels in the evaluation of training (DeSimone and Werner, 2012):

a. "Reaction (Level 1) At this level, the focus is on the trainee perceptions about a program and its effectiveness. This is useful information. Positive reaction to atraining program may make it easier to encourage employees to attend future programs.

b. Learning (Level 2) This is important criterion that an effective HRD program should satisfy. Measuring whether someone has learned something in training may involve a quiz or test-clearly a different method from assessing the participants' reaction to the program.

c. Behaviour (Level 3) This is also a critical measure of training success. If learning does not transfer to the job, the training effort cannot have an impact on employee or organization effectiveness. Observation of the trainee's on-the-job behaviour or viewing organizational records. 
d. Result (Level 4) Meeting this criterion is considered the bottom line as far as most managers are concerned. It is also the most challenging level to assess, given that many things beyond employee performance can affect organizational performance. Typically at this level, economic and operating data are collected and analysed".

\section{Research Method}

This research uses the quantitative descriptive method to provide a description of the result of evaluation of ESQ 165 Training. Data-gathering technique uses questionnaires distributed among members of the Subregional Police of Ciamis who have participated in ESQ 165 Training, observation and interviews. The result data of the questionnaires are analysed by using descriptive statistics for measures of central tendency or central location of a distribution by using mode and mean. Population of the research is 500 persons. By using Slovin's (Silalahi, 2009:276) formula with the error tolerance of 5\%, then the number of samples obtained in this research is 223 respondents.

$$
n=\frac{500}{1+500(0.05)^{2}}=222.2=223 \text { respondents }
$$

Questionnaires are distributed based on the Likert Scale, in which each respondent was asked to give the answer to a question. There are 5 variations of the answers, $1=$ Strongly Disagree, 2 = Disagree, 3 = Neither Agree nor Disagree, $4=$ Agree, $5=$ Strongly Agree.

\section{Findings}

\subsection{Biodata of Respondents}

There are 7 kinds of main information on the respondents, i.e.: (1) Sex: Respondents consist of $76 \%$ male and $24 \%$ female, (2) Age: The ages of the respondents are $7 \%$ of 19 years old or below, $41 \%$ between $20-30$ years old, $24 \%$ between $31-40$ years old, $15 \%$ between 41-50 years old, and 13\% over 50 years old, (3) Latest Education: Respondents consist of $75 \%$ high school graduates, $23 \%$ bachelor's degree graduates, $1 \%$ associate degree graduates, and $1 \%$ elementary school graduates, (4) Length of Service: There are $42 \%$ of respondents who have served for 10 years or less, $30 \%$ of respondents who have served for 20 years or less, $28 \%$ of respondents who have served for more than 20 years, (5) Work Unit: Respondents come from various work units, such as the units of $4 \%$ Drugs, $19 \%$ Traffic, 8\% Criminal Investigation, 4\% Propam (Security), 15\% Sabhara (the unit which is responsible to protect, to guard, and to serve the public), $4 \%$ General Affairs and Finance, and 46\% others (Resources, etc.), (6) Rank: Respondents consist of $70 \%$ noncommissioned officers, 19\% officers, 11\% others, (7) Position: 64\% of respondents are members of unit works, $10 \%$ of respondents are chiefs of unit works, $26 \%$ others.

\subsection{Reaction Level}

Reaction can be based on impression, opinions, and attitudes, and they identify how much the participants like the program, including its content, the trainer, the methods used and the surrounding in which the training took place (Stone, 2005).

Table 1 Opinion of the Reaction Level of ESQ 165 Training

\begin{tabular}{|c|l|c|c|c|c|c|}
\hline No & \multicolumn{1}{|c|}{ Statement } & $\mathbf{1}$ & $\mathbf{2}$ & $\mathbf{3}$ & $\mathbf{4}$ & $\mathbf{5}$ \\
\hline \multicolumn{1}{|c|}{ 1) Content } & & & & & \\
\hline 1 & Enthusiastic in participating in the activities of ESQ 165 Training. & $1 \%$ & $1 \%$ & $8 \%$ & $61 \%$ & $29 \%$ \\
\hline 2 & Material accords with the expectation. & $0 \%$ & $1 \%$ & $12 \%$ & $72 \%$ & $14 \%$ \\
\hline 3 & Material is useful in performing the duties. & $0 \%$ & $2 \%$ & $9 \%$ & $67 \%$ & $22 \%$ \\
\hline
\end{tabular}




\begin{tabular}{|c|c|c|c|c|c|c|}
\hline & Mean & $0.3 \%$ & $1.3 \%$ & $9.7 \%$ & $66.7 \%$ & $21.7 \%$ \\
\hline \multicolumn{7}{|c|}{ 2) Trainers } \\
\hline 4 & Clearly deliver the material. & $1 \%$ & $1 \%$ & $10 \%$ & $68 \%$ & $21 \%$ \\
\hline 5 & Systematically deliver the material. & $1 \%$ & $2 \%$ & $12 \%$ & $68 \%$ & $17 \%$ \\
\hline 6 & Have a broad outlook on the material. & $1 \%$ & $1 \%$ & $9 \%$ & $69 \%$ & $20 \%$ \\
\hline 7 & Have a good ability in answering each question asked by the respondent. & $1 \%$ & $1 \%$ & $14 \%$ & $67 \%$ & $17 \%$ \\
\hline 8 & Affirm the material to make it easier to understand for me. & $1 \%$ & $1.3 \%$ & $11.3 \%$ & $68 \%$ & $18.8 \%$ \\
\hline \multirow[t]{2}{*}{9} & Motivate the participants to improve their knowledge. & $1 \%$ & $1 \%$ & $10 \%$ & $68 \%$ & $21 \%$ \\
\hline & Mean & $1 \%$ & $1 \%$ & $2 \%$ & $68 \%$ & $19 \%$ \\
\hline \multicolumn{7}{|c|}{ 3) Method } \\
\hline 10 & The method used has been correct. & $1 \%$ & $1 \%$ & $9 \%$ & $69 \%$ & $20 \%$ \\
\hline 11 & Audio-visual media are in a good condition. & $1 \%$ & $1 \%$ & $10 \%$ & $72 \%$ & $17 \%$ \\
\hline \multirow[t]{2}{*}{12} & Audio-visual media are very helpful for understanding the material. & $1 \%$ & $0 \%$ & $13 \%$ & $69 \%$ & $18 \%$ \\
\hline & Mean & $1 \%$ & $1 \%$ & $11 \%$ & $70 \%$ & $18 \%$ \\
\hline \multicolumn{7}{|c|}{ 4) Surroundings in which Training TookPlace } \\
\hline 13 & Training rooms are comfortable & $1 \%$ & $1 \%$ & $10 \%$ & $68 \%$ & $21 \%$ \\
\hline 14 & Seats are comfortable & $1 \%$ & $2 \%$ & $12 \%$ & $68 \%$ & $17 \%$ \\
\hline 15 & Lighting is good & $1 \%$ & $1 \%$ & $9 \%$ & $69 \%$ & $20 \%$ \\
\hline \multirow[t]{2}{*}{16} & Temperature of the rooms is fine & $1 \%$ & $1 \%$ & $14 \%$ & $67 \%$ & $17 \%$ \\
\hline & Mean & $1 \%$ & $1 \%$ & $11,3 \%$ & $68 \%$ & $19 \%$ \\
\hline
\end{tabular}

The result of the research indicates that:

1) Content. Based on the data, $90 \%$ of respondents agree and strongly agree that they are very enthusiastic about participating in the training. As many as $87.5 \%$ of respondents state they agree and strongly agree that the material of ESQ has met their expectation and it is useful for performing their duties.

2) Trainer. Based on the data, $87 \%$ of respondents state they agree and strongly agree that the trainers are able to deliver the material clearly and systematically. Trainers are considered to have a broad outlook and a good ability in answering each question. Trainers are also considered to be emphatic, which is shown by giving motivation to the participants and affirmation of the material to make it easier for the respondents to understand the material. Based on the result of the observation and interviews, we obtain the information that each training is delivered by 1 main trainer and 2 associate trainers. The trainers have a good ability in delivering the material, particularly in the aspects of intonation and adjusting the volume of their voices through the mixer when they emphasize the material considered important. Trainers have the ability to play with the emotion of participants. During the contemplation session, the explanation of the trainers is able to make all participants cry, and on other hand the trainers are also able to make the participants laugh when they deliver an entertaining material. The training, which is conducted for 2 days, is perceived as not boring by the participants because in delivering the material, the trainers alternate with ice breaking and door prize awarding which give a cheerful atmosphere.

3) Methods. Based on the data of the result of questionnaires, $88 \%$ of respondents state they agree and strongly agree that the training method has been correct. Audio-visual media are in a good condition, and even some respondents state that ESQ 165 Training is equipped with sophisticated presentation technology. The presentation of the material is accompanied with music that can help respondents indulge themselves in experiencing the material. Meanwhile, the use of multimedia in delivering the material is considered to be helpful by the respondents for understanding the material.

4) Surroundings in which Training Took Place relate to the indicator of comfort. Based on the data $87 \%$ of respondents state they agree and strongly agree that they feel comfortable with the setting of the rooms, seats, lighting and temperature of the room. Based on the result of the observation, there is no lighting during the presentation of the 
material, and the light is obtained from the screen in order that the participants will focused on the training material.

In general, the result of the evaluation of reaction level shows that $88 \%$ of respondents like ESQ 165 Training, seen from the sides of material, trainers, methods and media used, and comfort of the training rooms. This research also measures whether there is a desire to participate in the advanced training and to recommend ESQ 165 Training to other people. Based on the data, $81 \%$ of respondents will participate in the advanced training of ESQ 165 because they consider it useful. However, there are $17 \%$ of respondents who still hesitate to participate again in the training. As many as $86 \%$ of respondents state they will recommend the training to their relatives.

\subsection{Learning Level}

In essence, the material of ESQ basic training is intended to build the commitment and sincerity which are realized in the 7 main virtues, namely honest, responsible, visionary, discipline, cooperative, righteous and caring. These characters are built based on the religious values which universally prevail. Therefore, evaluation on the learning level emphasizes on the aspect of the understanding of the 7 main virtues. The result of the questionnaires is as follows:

Table 2 Opinion of the Understanding on the Materials of ESQ 165 Training

\begin{tabular}{|c|c|c|c|c|c|c|}
\hline No & Statement & 1 & 2 & 3 & 4 & 5 \\
\hline 1 & An understanding on emotional quotient & $1 \%$ & $1 \%$ & $6 \%$ & $71 \%$ & $21 \%$ \\
\hline 2 & An understanding on intellectual quotient & $0 \%$ & $1 \%$ & $8 \%$ & $71 \%$ & $21 \%$ \\
\hline 3 & An understanding on spiritual quotient & $0 \%$ & $0 \%$ & $7 \%$ & $69 \%$ & $24 \%$ \\
\hline 4 & Improvement of the knowledge on religion & $1 \%$ & $1 \%$ & $8 \%$ & $67 \%$ & $24 \%$ \\
\hline 5 & An understanding on the importance of honesty in performing my work & $1 \%$ & $0 \%$ & $6 \%$ & $62 \%$ & $31 \%$ \\
\hline 6 & An understanding on the importance of responsibility in performing my work & $0 \%$ & $1 \%$ & $5 \%$ & $70 \%$ & $24 \%$ \\
\hline 7 & An understanding on the importance of having long-term thoughts (visionary) & $1 \%$ & $1 \%$ & $6 \%$ & $68 \%$ & $24 \%$ \\
\hline 8 & An understanding on the importance of discipline & $0 \%$ & $1 \%$ & $6 \%$ & $70 \%$ & $24 \%$ \\
\hline 9 & An understanding on the importance of cooperation to reach a goal & $0 \%$ & $1 \%$ & $8 \%$ & $67 \%$ & $24 \%$ \\
\hline 10 & An understanding on the importance of being fair to another human being & $0 \%$ & $1 \%$ & $6 \%$ & $68 \%$ & $25 \%$ \\
\hline 11 & An understanding on the importance of caring to another human being & $0 \%$ & $1 \%$ & $5 \%$ & $68 \%$ & $27 \%$ \\
\hline \multicolumn{2}{|r|}{ Mean } & $0.4 \%$ & $0.8 \%$ & $6.5 \%$ & $68.1 \%$ & $24.5 \%$ \\
\hline
\end{tabular}

Based on the data in Table 2, 93\% of respondents state they agree and strongly agree that ESQ 165 Training helps them to give the understanding related to the 7 main virtues, which are universal values. ESQ 165 Training is able to give the spiritual meaning of each work. The 7 main virtues are helpful to make vision, mission and values of the company as the motivation in work so that they will not merely pursue incentives.

Based on the result of the observation, at the early stage the participants (zero mind process) are provided with the material on inner journey and outer journey, which, in essence, invites the participants to conceive how great the universe is and how tiny we are. It aims to touch the feeling so that the heart becomes tender. The heart that up to now is hard and arrogant is expected to be tender again after seeing the greatness of the One and Only God.

ESQ 165 Training does not allow the trainees to take note on the material being delivered. The participants are encouraged to listen, understand, feel and experience each material delivered. The process of understanding and experiencing the material gives a very good impression to the trainees, particularly due to the presentation of the material through sophisticated multimedia. 


\subsection{Behaviour Level}

In order to find out the evaluation behavioural level, an observation and interviews are conducted, and questionnaires are utilized to find the opinion of the respondents on the level. Basically, the aspect of behaviour level measures the level of changes in attitudes, behaviour and motivation. The changes in the attitude of the members of the Subregional Police of Ciamis cannot be separated from the role of the Chief of the Subregional Police of Ciamis as the agent of change. He has stipulated some policies in order to change the behaviour of the members of the Subregional Police of Ciamis, among other things:

- To make spiritual values as the motivation in work, through: (1) the reciting of asmaulhusna (beautiful names of Allah Swt.) at the morning assembly (for Muslims). The reciting of asmaulhusna has a purpose to remember the greatness of Allah Swt. so that it becomes the motivation that work is not just orientated to material interest but it is a religious obligation. When someone considers that work is a religious obligation, it is expected that the 7 main virtues will spontaneously emerge. (2) Religious gathering which is often directly led by the Chief of the Subregional Police of Ciamis. It also has a purpose to remind that work is a religious obligation.

- To make the 7 main virtues as the character of the members of the Subregional Police of Ciamis. (1) At the moment, organization values of the Regional Police of Ciamis refer to the 7 main virtues introduced in ESQ 165. The values of the Subregional Police of Ciamis are honesty, integrity, cooperation, hierarchy and loyalty. (2) Every morning these values are pledged by the members of the Subregional Police of Ciamis as the process of cultural internalisation. (3)They have a habit of cleaning the office and the surroundings which will build the character of cleanliness loving, cooperation and devotion in work.(4) As the agent of law enforcement, the members of the Police must respect the law values and norms; their behaviour must be the model for the public. Therefore, the Chief of the Subregional Police regards the discipline of the members of the Subregional Police of Ciamis must be improved, among other things, by routinely checking the equipment, facilities and attribute of the members of the Subregional Police of Ciamis. The result of the checking shows that the majority of the members of the Subregional Police of Ciamis have followed the rules. (5) The value of cooperation has become the key for the the members of the Subregional Police of Ciamis in serving and guarding the public. In this case the Subregional Police of Ciamis has conducted many formal and informal activities which involve the public in order to bring about security and order based on the partnership with the public.

The Chief of the Subregional Police of Ciamis has adopted a system to follow up on the change of behaviour to be more professional in their service to the public by: (1) enforcing the rules on the discipline of police code and ethics which have an effect on a decrease of violations of the discipline of ethical code of police committed by the members of the Subregional Police of Ciamis; (2) giving reward or punishment to all members of the Subregional Police of Ciamis to enhance their motivation to do their duties as the member of the Indonesian National Police; (3) establishing the career in accordance with the principles of transparency and the right man on the right place, (4) optimizing the standard operating procedures (SOP) to avoid procedural faults in their daily performance at work.

At the behaviour level, the opinion of the respondents is also measured in a questionnaire. Based on the data, $86.6 \%$ of respondents agree and strongly agree that the material of ESQ 165 Training has changed their attitude and behaviour. They feel more honest and more responsible. They always consider the long-term impact of each of their 
behaviour. They are more disciplined at work and more intensively involve in teamwork. They try to be fairer and more caring towards others.

The result of the interview with some members of the Subregional Police Ciamis indicates that ESQ basic training has an effect on their behaviour, but maintaining the behaviour needs the support of a good system, among others, through the commitment of the leaders. Respondents state that so far the Chief of the Subregional Police of Ciamis has become the role model of the behavioural change of the members of the Subregional Police. $\mathrm{He}$ is considered as a figure close to his subordinates, and he frequently visits the ground to find out the problems faced by his members. The Chief of the Subregional Police actively leads the morning assembly and religious gathering. Moreover, respondents also consider that as a leader, the Chief of the Subregional Police is able to give constructive directions for the improvement of the organization.

\subsection{Result Level}

Result level will measure to what extent the effectiveness of ESQ 165 Training improves the performance of organization. In this research, the result level has not been conducted entirely towards the performance of the Subregional Police of Ciamis because ESQ 165 Training has not yet been conducted for a full year so that the data of the performance have not been complete. In addition, as of now just $62 \%$ of members of the Subregional Police of Ciamis have attended ESQ 165 Training.

The result of the observation shows that although ESQ 165 Training has not yet conducted until 2015, it has shown the change of behaviour among the members of the Subregional Police of Ciamis to be a better one. Some members directly convey their appreciation on the service of the members of the police via short message services (SMS). The followings are the points of the SMS:

- Mrs.Sumiati appreciated the service of the Subregional Police of Ciamis because her son had been very well served when he tried to arrange for his police record (SKCK). Moreover, the officer refused the service fee given personally by $\mathrm{Hj}$. Sumiati.

- Mr.Wagino appreciated the members of the Police that refused the service fee he gave personally.

- Mr.Kurniawan, Mr.Suwandi, Mr.Irsad, Mr.Dani, Mr.Syahroni, Mr. Akbar, NN expressed their extraordinary pride in the service of the members of the Subregional Police of Ciamis in making the driving license. Mr.Suwandi added that the members of the Subregional Police of Ciamis sincerely served the public.

Another impact felt by the public is they feel closer to the police because in many occasions they are involved in the effort to maintain mutual security and order.

As the comparative materials, in the result level, the opinion of the respondents is also measured in a questionnaire with the following result:

Table 3 Opinion of the Respondents on the Effects of ESQ 165 Training

\begin{tabular}{|c|c|c|c|c|c|c|}
\hline No & Statement & 1 & 2 & 3 & 4 & 5 \\
\hline 1 & I maintain the security of the public more intensively. & $0 \%$ & $1 \%$ & $9 \%$ & $76 \%$ & $14 \%$ \\
\hline 2 & I maintain the order of the public more intensively. & $0 \%$ & $1 \%$ & $9 \%$ & $77 \%$ & $13 \%$ \\
\hline 3 & I try to enforce the law as justly as possible. & $1 \%$ & $1 \%$ & $9 \%$ & $74 \%$ & $16 \%$ \\
\hline 4 & $\begin{array}{l}\text { I try to the maximum to encourage the public to improve their awareness and obedience to } \\
\text { the law. }\end{array}$ & $1 \%$ & $1 \%$ & $8 \%$ & $70 \%$ & $20 \%$ \\
\hline 5 & I perform my duties seriously. & $1 \%$ & $1 \%$ & $9 \%$ & $72 \%$ & $18 \%$ \\
\hline & Mean & $0.6 \%$ & $1 \%$ & $8.8 \%$ & $73.8 \%$ & $16.2 \%$ \\
\hline
\end{tabular}


Table 3 shows that $90 \%$ of respondents feel that after participating in ESQ 165 Training, they perform their duties seriously. It is affected by the spiritual values which have become the motivation of the members of the Subregional Police of Ciamis at work.

\section{Conclusion}

Based on the result of the research, as spiritual-engineering based motivation training, 165 Training ESQ can be recommended as one of the training methods that can be utilized in character building. However, the change of behaviour is not an instant process so that the values built in the training need to be internalised to become a culture. Here lies the importance of the commitment of a leader in building the character of the members of the organization towards the expected behaviour.

Recommendation of the research, a research on training to change the employee behaviour will be more effective if it uses the longitudinal survey considering the behaviour cannot be changed instantly so that it needs repeated observation of the same variables over long periods of time in order to find out the behavioural and result levels. Similar research can also be conducted if all members of the Subregional Police of Ciamis have attended the training, considering after the Subregional Police of Ciamis has signed an MoU with ESQ Leadership Center in 2015, as of now just $62 \%$ of members of the Subregional Police of Ciamis have had the opportunity to attend the training. Therefore, the performance of the Subregional Police of Ciamis has not yet fully affected by the members who have attended ESQ 165 Training.

\section{References}

Berman Evan M., James S. Bowman, Jonathan P. Wesr, Montgomery R. Van Wart. (2010). Human Resources Management in Public Service: Paradoxes, Process, And Problems. California: Sage.

DeSimone, Randy L., Jon M. Werner. (2012). Human Resource Management. Canada: Nelson Education. Pages 36-173.

Dessler, Gary and Tan Chwee Huat.(2009). Human Resources Management. Singapore: Printice Hall.

Hays, Steven W., Richard C. Kearney, Jerrell D. Coggburn.(2009). Public Human Resource Management. Singapore: Pearson Edition.

Silalahi, Ulber. (2009). Metode Penelitian Sosial. Bandung: PT. Refika Aditama

Stone, Raymond J. Human Resource Management. (2005). Milton Qld: John Wiley \& Sons Australia, Ltd. Pages 355-372. 